\title{
Characterizing the species composition of European Culicoides vectors by means of the Köppen-Geiger climate classification
}

\author{
Katharina Brugger ${ }^{*}$ and Franz Rubel
}

\begin{abstract}
Background: Biting midges of the genus Culicoides spp. (Diptera: Ceratopogonidae) are vectors for the Bluetongue virus, the African horse sickness virus and the recently emerged Schmallenberg virus. Here, species of the C. obsoletus complex, the C. pulicaris complex and C. imicola were considered. The objective was to compile a map of these Culicoides species and their relation to the popular climate classification defined by Wladimir Köppen and Rudolf Geiger to provide a quick view on the species composition in Europe.

Findings: Major parts of Central and Northern Europe are covered by a warm temperate fully humid climate, characterized by warm summers. For this so-called Cfb climate fractions of $89 \%$ C. obsoletus complex and $11 \%$ C. pulicaris complex were estimated. Further investigations comprise the continental climate Dfb (76\% C. obsoletus, $24 \%$ C. pulicaris), the warm temperate climate with hot summers Cfa (35\% C. obsoletus, $65 \%$ C. pulicaris), the warm temperate dry climate, characterized by warm summers Csb (38\% C. obsoletus, 51\% C. pulicaris, 11\% C. imicola) and the warm temperate dry climate with hot summers Csa of the Mediterranean area (11\% C. obsoletus, $12 \%$ C. pulicaris, $77 \%$ C. imicola).
\end{abstract}

Conclusions: A highly significant association coefficient of $R_{V}=0.64$ (Cramer's V) confirms the correlation between Culicoides spp. and climate zones. Moreover, climate projections for the end of the century give an impression on expected changes in the European Culicoides spp. composition.

Keywords: Bluetongue, Culicoides obsoletus complex, C. pulicaris, C. imicola, Climate

\section{Background}

Within the past few years Culicoides species compositions were investigated in many national studies comprising different climate regions. However, a generalised map for Europe is missing. Such a map may be helpful especially for non-entomologists who want to get a quick view on Culicoides vectors. Additionally, experts get a first qualitative impression on the species composition expected for different climate change scenarios. To compile such a map, the authors used their own monitoring data [1] as well as data from the literature [2-13]. In contrast to the detailed national studies mentioned above, a largescale analysis is presented here. To obtain a clear statistical signal for the big picture all details were removed

\footnotetext{
* Correspondence: katharina.brugger@vetmeduni.ac.at

Institute for Veterinary Public Health, University of Veterinary Medicine Vienna, Veterinärplatz 1, 1210, Vienna, Austria
}

from the data by averaging. The focus is on the main Bluetongue vector species, those of the $C$. obsoletus complex, the $C$. pulicaris complex and C. imicola [14]. It is further known that midges of the $C$. obsoletus complex are most abundant in the fully humid climates of Central and Northern Europe, while C. imicola are the main vectors for the Bluetongue virus in the dry Mediterranean area. A North-south orientated gradient in the species composition is predominant. Quantitative relationships to climate zones, however, are still missing. So far Culicoides distribution maps are so-called presence/absence maps as recently presented by e.g. [15] or maps depicting the density of the main Bluetongue vectors [1].

Here, this gap is closed by relating the 3 species complexes to 5 climate classes of the warm temperate and continental climates defined by the well-known KöppenGeiger climate classification [16]. A digital version of this climate classification was compiled by [17] and projected

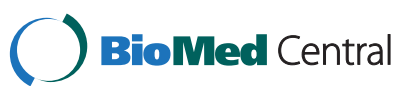


to the future by [18]. It is publicly available on a $0.5^{\circ}$ regular longitudinal/latitudinal grid (http://koeppengeiger.vu-wien.ac.at). Each climate is characterized by means of temperature and precipitation described by a three-letter code as documented by [17]. Because Culicoides spp. are the main vectors of the Bluetongue virus, which is observed almost exclusively in warm temperate and continental climates, we focus on these main climates. The warm temperate climate is denoted by the first letter $\mathrm{C}$, the continental climate by $\mathrm{D}$. The second letter distinguishes between humid (f) and dry (s) conditions and the third letter between warm (b) and hot (a) summers. Thus, the 5 European climate classes considered in this study are Cfb, Dfb, Cfa, Csb and Csa, respectively (Figure 1).

\section{Findings}

Although many Culicoides spp. monitoring programs have been undertaken in recent years, only some of them provide unambiguous information on the species composition related to specific climate zones. Data from these monitoring programs, conducted between 2000 and 2011, were summarized in Table 1 . Unless the Culicoides counts were not pooled by the authors of these studies, they were grouped according to [19] into Culicoides obsoletus complex (comprising C. obsoletus, C. scoticus, C. dewulfi, and C. chiopterus), Culicoides pulicaris complex (comprising C. pulicaris, C. impunctatus, C. punctatus, C. grisescens, and C. newsteadi), Culicoides imicola and other Culicoides species. For a clear representation the latter were excluded from the statistics.

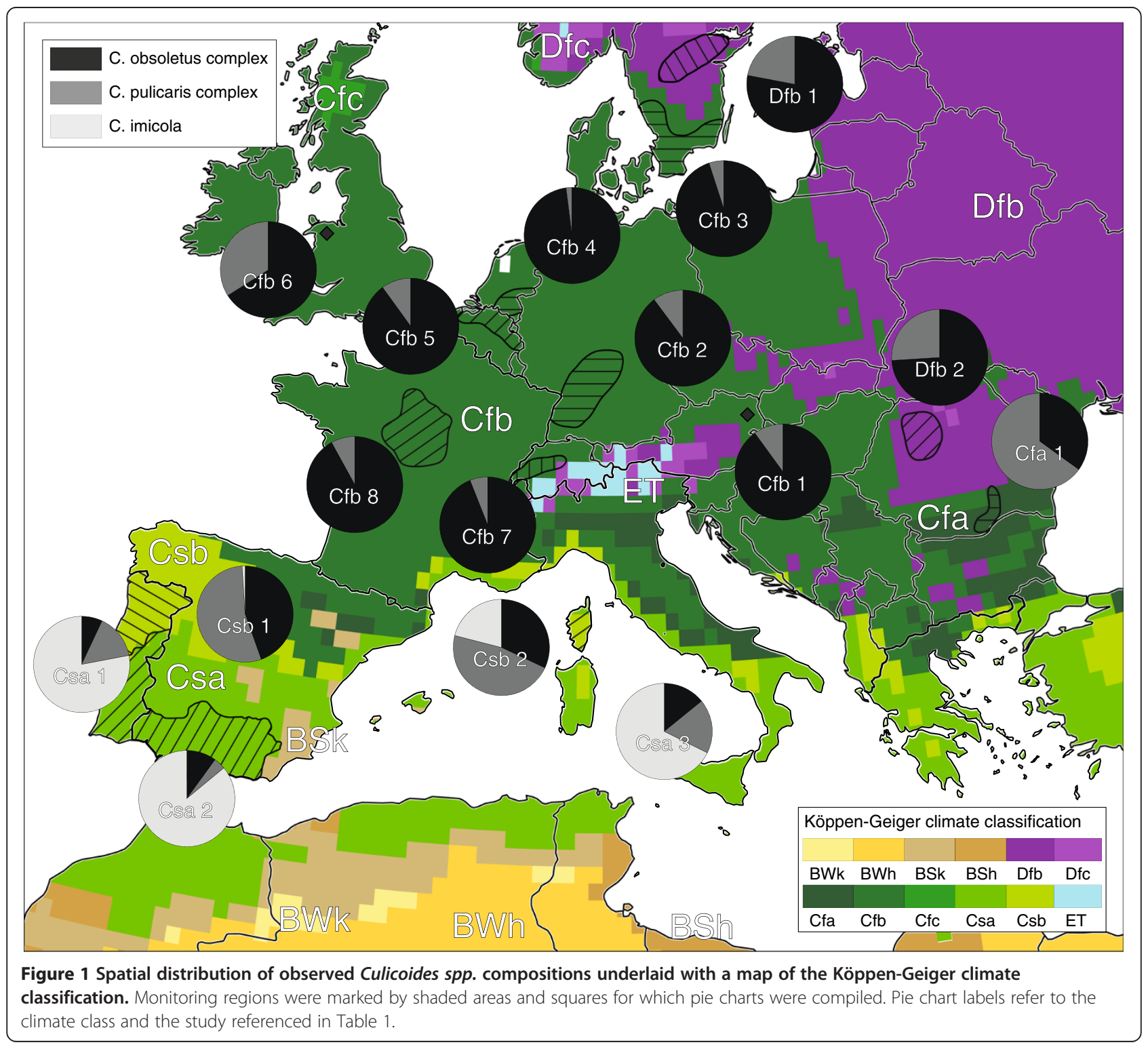


Table 1 Culicoides spp. monitoring data for different climate zones used in this study

\begin{tabular}{|c|c|c|c|c|c|c|}
\hline Climate & Country & Number of traps & Type of traps ${ }^{1}$ & Sampling period & Sampling interval & Reference \\
\hline Cfb 1 & AT & 1 & OVI & $2009-2011$ & Daily & [1] \\
\hline $\mathrm{Cfb} 2$ & $\mathrm{DE}$ & 9 & BG & 2007-2008 & Day 1-8 of each month & [2] \\
\hline Cfb 3 & SE & 12 & OVI & $2008-2009$ & Weekly & [3] \\
\hline Cfb 4 & $\mathrm{NL}$ & 4 & LP & 2005-2006 & Continuously and emptied once a week & [4] \\
\hline Cfb 5 & $\mathrm{BE}$ & 29 & CDC & 2006 & Two nights twice a week & [5] \\
\hline $\mathrm{Cfb} 6$ & UK & 35 & OVI & 2008 & Three trapping nights & [6] \\
\hline $\mathrm{Cfb} 7$ & $\mathrm{CH}$ & 4 & OVI & $2008-2011$ & Weekly & [7] \\
\hline $\mathrm{Cfb} 8$ & FR & $\mathrm{n} / \mathrm{a}$ & OVI & 2010 & Weekly & [8] \\
\hline Dfb 1 & SE & 2 & OVI & 2008-2009 & Weekly & [3] \\
\hline Dfb 2 & $\mathrm{RO}$ & 3 & OVI & 2008 & Weekly in May & [9] \\
\hline Cfa 1 & $\mathrm{RO}$ & 3 & OVI & 2008 & Weekly in May & [9] \\
\hline Csb 1 & PT & 35 & OVI & $2000 / 2001$ & Two to seven consecutive nights & {$[10]$} \\
\hline Csb 2 & FR & 12 & OVI & 2002 & One night every three weeks & [11] \\
\hline Csa 1 & PT & 43 & OVI & $2000 / 2001$ & Two to seven consecutive nights & {$[10]$} \\
\hline Csa 2 & ES & 52 & CDC & $2007-2008$ & Weekly & [12] \\
\hline Csa 3 & IT & $n / a$ & OVI & $2000-2003$ & Weekly & [13] \\
\hline
\end{tabular}

'OVI - Onderstepoort Veterinary Institute black light suction trap; CDC - new standard miniature black light trap (model 1212), John W. Hook Company, USA; BG BG-Sentinel mosquito trap, Biogents AG, Germany; LP - Liberty Plus $\mathrm{CO}_{2}$ baited counterflow trap, America Biophysics Co., USA.

The fractions of the three species complexes were calculated separately for each climate zone and each study is referenced in Table 1, respectively. Finally, the mean fractions calculated from all studies are summarized in Table 2. Note, that the sum of fractions in each climate zone is 1 (100\%).

Figure 1 provides a quick view on the composition of European Culicoides spp. and their relation to climate. Major parts of Central and Northern Europe are covered by a warm temperate (green areas) and a continental or snow (violet areas) climate for which the Culicoides spp. compositions were investigated. The fully humid climates characterized by warm summers are denoted by $\mathrm{Cfb}$ and Dfb. The typical species composition of Cfb climate comprises $89 \%$ midges of the C. obsoletus complex and $11 \%$ of the C. pulicaris complex. For the Dfb climate $76 \%$ C. obsoletus and $24 \%$ C. pulicaris were estimated.
No C. imicola were observed in Cfb and Dfb climates. The similar climate zone with hot summers is denoted by Cfa, for which on average $35 \%$ C. obsoletus and $65 \%$ C. pulicaris were found. The Csb climate, the warm temperate dry climate characterized by warm summers, is mainly observed in Northern Spain and Portugal, but also in the inland of Greece and Italy. It is characterized by a species composition of $38 \%$ C. obsoletus, $51 \%$ C. pulicaris and $11 \%$ C. imicola. For the dry climate with hot summers, usually known as Mediterranean or Csa climate, a mean fraction of $11 \%$ C. obsoletus, $12 \%$ C. pulicaris and $77 \%$ C. imicola was observed (Table 2). The association coefficient of $\mathrm{R}_{\mathrm{V}}=0.64$ (Cramer's V) confirms the correlation between Culicoides spp. and climate zones. Because of the huge sampling size this correlation is highly significant $(\mathrm{p}<0.01)$. Note that the latter may not be calculated from Table 2 where - for a

Table 2 Contingency table for Culicoides spp. fractions related to different climate zones resulting in an association coefficient (Cramer's V) of $R_{V}=\mathbf{0 . 6 4}$

\begin{tabular}{|c|c|c|c|c|}
\hline \multirow[t]{2}{*}{ Climate } & \multicolumn{3}{|c|}{ Culicoides species complex } & \\
\hline & obsoletus & pulicaris & imicola & \\
\hline Cfb (warm temperate, moist, warm summer) & 0.89 & 0.11 & 0.00 & 1.00 \\
\hline Dfb (continental, moist, warm summer) & 0.76 & 0.24 & 0.00 & 1.00 \\
\hline Cfa (warm temperate, moist, hot summer) & 0.35 & 0.65 & 0.00 & 1.00 \\
\hline Csb (warm temperate, dry, warm summer) & 0.38 & 0.51 & 0.11 & 1.00 \\
\hline \multirow[t]{2}{*}{ Csa (warm temperate, dry, hot summer) } & 0.11 & 0.12 & 0.77 & 1.00 \\
\hline & 2.49 & 1.63 & 0.88 & 5.00 \\
\hline
\end{tabular}



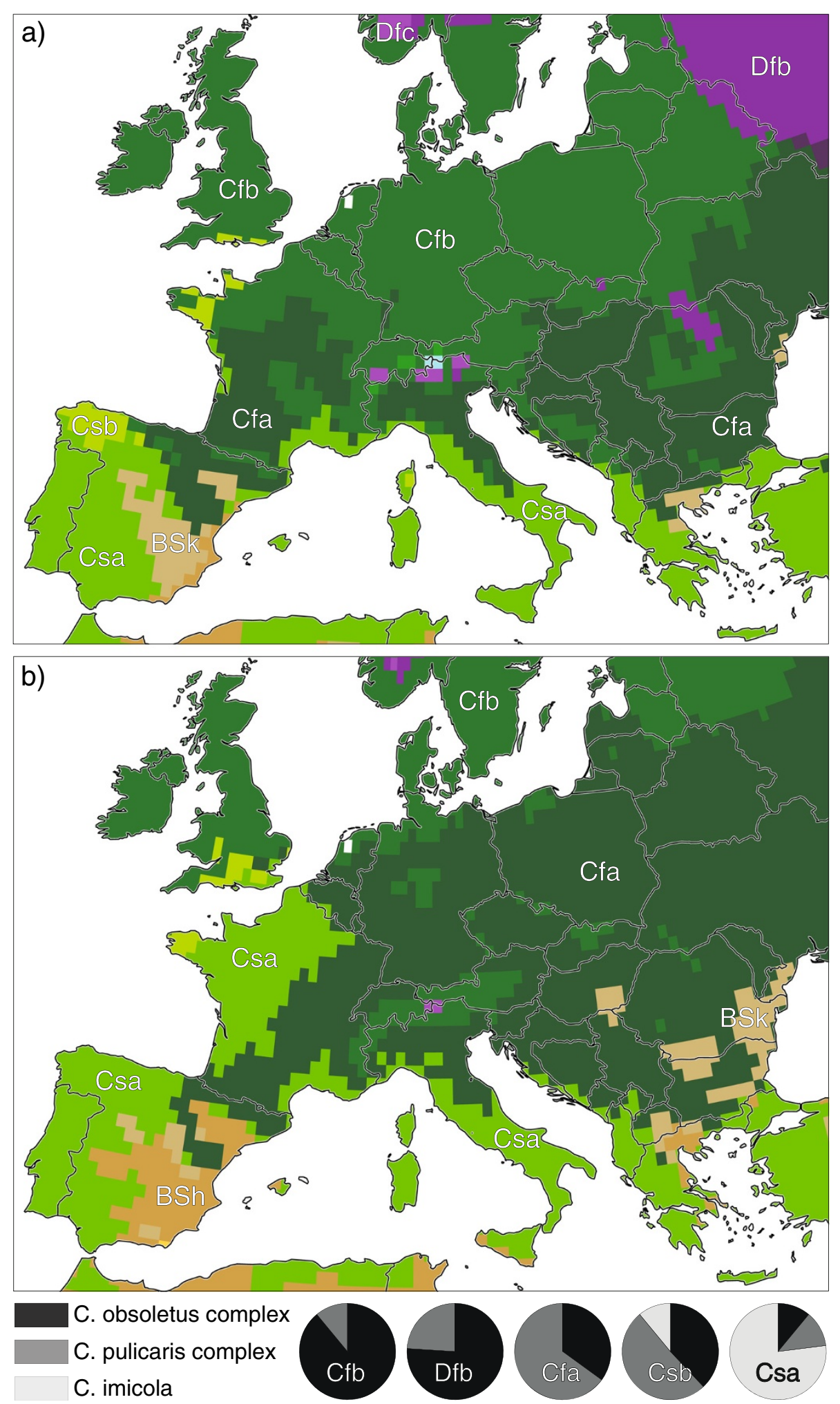

Figure 2 Projected Köppen-Geiger climate classifications for the best-case (a) and the worst-case (b) IPCC emission scenario. Period 2076-2100, after [18]. 
better representation - fractions instead of absolute numbers were presented. Generally, the fractions of $C$. obsoletus decrease while those of $C$. imicola increase from $\mathrm{Cfb}$ to Csa climate (North-south gradient). The fraction of C. pulicaris is maximal in $\mathrm{Cfa}$ and $\mathrm{Csb}$ climate.

\section{Conclusions}

A quick view on the composition of the most important Culicoides spp. in Europe was introduced. To the knowledge of the authors this is the first map on this topic. The results are widely consistent with previously published maps such as the possible distribution of C. imicola in Spain [15], the presence/absence maps of C. imicola around the Mediterranean area predicted from sites in Portugal [20] and the Iberian Peninsula [21] or the northern and southern distribution limits for C. obsoletus, C. pulicaris and C. imicola groups [22].

Although a significant correlation between Culicoides spp. composition and climate zones was demonstrated, the spatial resolution applied is rather coarse and may be refined by using future higher resolution climate maps and advanced statistical approaches such as niche modeling (e.g. [23]). A further weak point of the study is that, due to the lack of other data sources, Culicoides counts from different trapping methods were mixed together. These comprise various black light suction trap types and a $\mathrm{CO}_{2}$ baited counterflow trap type (Table 1). More consistent results may be obtained by using only one standardized trapping method. Improved analyses should also be based on extensive data to be compiled from national sources as currently conducted within the EMIDA VICE project (Carsten Kirkeby, pers. communication).

Finally, Figure 2 may be used to compare current (Figure 1) with expected Culicoides spp. compositions (Table 2) by means of Köppen-Geiger climate classifications for the period 2076-2100 [18]. The projections were compiled from multi-model ensemble predictions of temperature and precipitation following the Intergovernmental Panel on Climate Change (IPCC) emission scenarios B1 (minor climate changes, called best-case scenario) and A1FI (major climate changes, called worst-case scenario).

After both scenarios the warm temperate climate shifts to the North and East, in which large areas covered by the fully humid climate with warm summers $(\mathrm{Cfb})$ will be replaced by the humid climate with hot summers (Cfa). Thus the future species composition in Central and Northern Europe will be characterized by a decreasing fraction of $C$. obsoletus and an increasing fraction of C. pulicaris. Another example concerns the dry climates $\mathrm{Csb}$ and Csa, which are projected to extend their ranges from Spain to Northern France resulting in a northward shift of the distribution of C. imicola. In arid regions, projected by the worst-case IPPC scenario for the south of the Iberian Peninsula and the Thessaloniki region in Greece (BSk and BSh climates in Figure 2), however, environmental conditions for C. imicola will worsen. As [24] stated soil moisture may be considered as a key environmental variable for the delineation of suitable $C$. imicola habitat. Thus, climate projections for the end of the century give an impression on expected changes of the Culicoides spp. composition. A final statement on epidemiological consequences concerning the shift in Culicoides spp. compositions, however, is rather speculative. As C. imicola is a confirmed field vector for the African horse sickness virus [25] and the BTV serotypes 1 , 2, 4, 6 and 9 [22], upcoming outbreaks might be occur in regions covered by Csa and Csb climates in future decades. On the other hand, changing vector competences (e.g. shorter extrinsic incubation periods due to global warming) and new virus serotypes may still lead to unforeseeable disease outbreaks. As an example for the latter, the BTV-8 outbreak in Central Europe 2006 is mentioned. It took place in $\mathrm{Cfb}$ climates, a region where C. imicola is absent.

\section{Competing interests}

The authors declare that they have no competing interests.

\section{Author's contributions}

The project was designed, the data analysed and the paper written by KB and FR. Both authors read and approved the final version of the manuscript.

\section{Acknowledgement}

The study was financed by Vet-Austria, a cooperation between the Austrian Federal Ministry of Health, the Austrian Agency for Health and Food Safety and the University of Veterinary Medicine Vienna.

Received: 29 August 2013 Accepted: 19 November 2013

Published: 22 November 2013

\section{References}

1. Brugger K, Rubel F: Bluetongue disease risk assessment based on observed and projected Culicoides obsoletus spp. vector densities. PLoS One 2013, 8:e60330.

2. Hörbrand T, Geier M: Monitoring of Culicoides at nine locations in Southern Germany (2007-2008). Parasitol Res 2009, 105(2):387-392.

3. Ander M, Meiswinkel R, Chirico J: Seasonal dynamics of biting midges (Diptera: Ceratopogonidae: Culicoides), the potential vectors of bluetongue virus, in Sweden. Vet Parasitol 2012, 184:59-67.

4. Takken W, Verhulst N, Scholte EJ, Jacobs F, Jongema $Y$, van Lammeren $R$ : The phenology and population dynamics of Culicoides spp. in different ecosystems in The Netherlands. Prev Vet Med 2008, 87(1-2):41-54.

5. De Deken G, Madder M, Deblauwe I, De Clercq K, Fassotte C, Losson B, Haubruge E, De Deken R: Vector monitoring at Belgian outbreak sites during the bluetongue epidemic of 2006. Prev Vet Med 2008, 123(87):64-73.

6. Kluiters G, Sugden D, Guis H, Mclntyre KM, Labuschagne K, Vilar MJ, Baylis M: Modelling the spatial distribution of Culicoides biting midges at the local scale. J Appl Ecol 2013, 50:232-242.

7. Kaufmann C, Steinmann I, Hegglin D, Schaffner F, Mathis A: Spatio-temporal occurrence of Culicoides biting midges in the climatic regions of Switzerland, along with large scale species identification by MALDI-TOF mass spectrometry. Parasit Vectors 2012, 5:246.

8. Balenghien T, Delécolle JC, Setier-Rio ML, Rakotaoarivony I, Alléne X, Venail R, Delécolle D, Lhoir J, Gardés L, Chavernac D, Mathieu B, Languille J, Baldet T, Garros C: Bluetongue - report on entomological surveillance in France in 2010. Bulletin épidémiologique, santé animale et alimentation 2010, 46:26-31.

9. Ioniță M, Mitrea I, Buzatu M, Dascălu L, lonescu A: Seasonal dynamics of haematophag arthropod populations (ticks and Culicoides spp.) - vectors 
of pathogens in animals and humans, in different areas of Romania (in Romanian). Lucrări Știintice Medicină Veterinară 2009, 52(11):629-636.

10. Capela R, Purse B, Pena I, Wittman E, Margarita Y, Capela M, Romao L, Mellor P, Baylis M: Spatial distribution of Culicoides species in Portugal in relation to the transmission of African horse sickness and bluetongue viruses. Med Vet Entomol 2003, 17(2):165-177.

11. Baldet T, Delécolle J, Mathieu B, de La Rocque S, Roger F: Entomological surveillance of bluetongue in France in 2002. Vet Ital 2004, 40(3):226-231.

12. Pérez JM, García-Ballester JA, López-Olvera JR, Serrano E: Monitoring bluetongue virus vectors in Andalusia (SW Europe): Culicoides species composition and factors affecting capture rates of the biting midge Culicoides imicola. Parasitol Res 2012, 111(3):1267-1275.

13. Goffredo M, Conte A, Meiswinkel R: Distribution and abundance of Culicoides imicola, obsoletus complex and pulicaris complex (Diptera: Ceratopogonidae) in Italy. Vet Ital 2004, 40(3):270-273.

14. Mellor PS, Carpenter S, White DM: Bluetongue Virus in the Insect Host. In Bluetonque. Edited by Mellor. Amsterdam: Academic Press; 2009

15. Peters J, De Baets B, Van Doninck J, Calvete C, Lucientes J, De Clercq EM, Ducheyne $E$, Verhoest NEC: Absence reduction in entomological surveillance data to improve niche-based distribution models for Culicoides imicola. Prev Vet Med 2011, 100:15-28.

16. Köppen W: Das Geographische System der Klimate (The Geographic System of Climates). In Handbuch der Klimatologie, Bd. 1, Teil C. Edited by Köppen W, Geiger R. Borntraeger, Berlin; 1936.

17. Kottek M, Grieser J, Beck C, Rudolf B, Rubel F: World map of the Köppen-Geiger climate classification updated. Meteorol Z 2006, 15:259-263.

18. Rubel F, Kottek M: Observed and projected climate shifts 1901-2100 depicted by world maps of the Köppen-Geiger climate classification. Meteorol Z 2010, 19:135-141.

19. Nolan DV, Carpenter S, Barber J, Mellor PS, Dallas JF, Mordue (Luntz) AJ, Piertney SB: Rapid diagnostic PCR assays for members of the Culicoides obsoletus and Culicoides pulicaris species complexes, implicated vectors of bluetongue virus in Europe. Vet Microbiol 2007, 124(1-2):82-94.

20. Tatem AJ, 159, Baylis M, Mellor PS, Purse BV, Capela R, Pena I, Rogers DJ: Prediction of bluetongue vector distribution in Europe and North Africa using satellite imagery. Vet Microbiol 2003, 97:13-29.

21. Baylis M, Mellor PS, Wittmann EJ, Rogers DJ: Prediction of areas around the Mediterranean at risk of bluetongue by modelling the distribution of its vector using satellite imaging. Vet Rec 2001, 149:639-643.

22. Purse BV, Mellor PS, Rogers DJ, Samuel AR, Mertens PPC, Baylis M: Climate change and the recent emergence of bluetongue in Europe. Nat Rev Microbiol 2005, 3(2):171-181.

23. Wiens JA, Stralberg D, Jongsomijt D, Howell CA, Snyder MA: Niches, models, and climate change: assessing the assumptions and uncertainties. Proc Natl Acad Sci USA 2009, 106(Suppl. 2):19729-19736.

24. Peters J, Conte A, Van Doninck J, Verhoest NEC, De Clerca E, Goffredo M, De Baets B, Hendrickx G, Ducheyne E: On the relation between soil moisture dynamics and the geographical distribution of Culicoides imicola. Ecohydrol 2013. doi:10.1002/eco.1383.

25. Mellor PS, Boorman J, Baylis M: Culicoides biting midges: their role as arbovirus vectors. Annu Rev Entomol 2000, 45:307-340.

\section{Submit your next manuscript to BioMed Central and take full advantage of:}

- Convenient online submission

- Thorough peer review

- No space constraints or color figure charges

- Immediate publication on acceptance

- Inclusion in PubMed, CAS, Scopus and Google Scholar

- Research which is freely available for redistribution

Submit your manuscript at www.biomedcentral.com/submit
C Biomed Central 